\title{
Nem soja, nem gaúcho: autonomia camponesa e governança ambiental na Resex Chapada Limpa/MA
}

DoI

http://dx.doi.org/10.11606/ 2179-0892.ra.2017.137320

\section{Diana Patrícia Mendes \\ e Benedito Souza Filho}

- Universidade Federal do Maranhão / São Luís, MA, Brasil

$\checkmark$ dipatriciamendes@gmail.com,bes045@gmail.com

\section{RESUMO}

O avanço do agronegócio no Leste do Maranhão, voltado para o plantio da soja, tem propiciado a destruição de amplas áreas de Cerrado, comprometendo a organização social e econômica das famílias residentes nas zonas de implantação desses empreendimentos. Tomando esse quadro para análise, o presente artigo busca entender os impactos desses empreendimentos na região, como propõe uma reflexão sobre os elementos que justificaram a criação da Reserva Extrativista Chapada Limpa que se localiza no município de Chapadinha/MA como estratégia de defesa de territórios. O estudo busca entender também os desafios de governança, uma vez que a autonomia das famílias ficou limitada pela participação do Estado como . 


\section{INTRODUÇÃO'}

O presente artigo representa um desdobramento das minhas atividades de pesquisa desenvolvidas no âmbito do projeto "Conflitos, Ação Coletiva e Gestão da Biodiversidade: os desafios da governança"2, coordenado pelo Prof. Dr. Benedito Souza Filho.

Este artigo é, portanto, resultado de uma pesquisa acadêmica inspirada no que Burawoy (2006) denominou de sociologia pública e que, em um contexto de mudança de paisagem derivada da ação dos agentes do agronegócio, privilegiou o diálogo com um público específico: famílias camponesas ameaçadas pelo avanço da sojicultura no Leste do Maranhão.

As reflexões aqui empreendidas buscam, por um lado, compreender o processo de luta e mobilização de famílias camponesas para a criação da Resex Chapada Limpa; por outro, visam entender os problemas relativos à autonomia das famílias após a criação da Resex, tomando como referência questões relativas à governança ambiental e territorial.

Vale destacar que a questão ambiental foi considerada como elemento importante para compreender os processos de transformação de áreas de tensão social em Unidades de Conservação (UC) não por enquadrar-se em uma ideia de preservacionismo, mas por sua relevância social e política, já que o avanço do agronegócio tem afetado a reprodução material e social de várias famílias da região Leste do Maranhão, onde se situa a Resex Chapada Limpa. Essas tensões surgem em decorrência da disputa envolvendo, por um lado, famílias camponesas que lutam para conservar áreas de cerrado e, de outro, pretensos proprietários ou os chamados gaúchos ${ }^{3}$ cujos interesses estão associados à venda de terras em zonas de chapada e à ampliação de áreas de cultivo da soja respectivamente. É justamente em função dessas situações de tensão social que segmentos camponeses têm pleiteado a criação de unidades de conservação de uso sustentável como forma de resolução dos problemas enfrentados com grileiros ou com agentes do agronegócio, notadamente do ramo da soja.

As análises aqui realizadas estão ancoradas no trabalho de campo desenvolvido em distintas etapas entre dezembro de 2012 e julho de 2014 no povoado Juçaral, localizado na Resex Chapada Limpa, distante aproximadamente $42 \mathrm{~km} \mathrm{da}$ sede do município de Chapadinha, no Maranhão. Juçaral é um povoado que se destacou pelo movimento de resistência ao desmatamento de áreas de chapada ${ }^{4}$ pelos chamados gaúchos. As famílias dessa e outras localidades mobilizaram-se em função de dependerem das áreas de chapada como indispensáveis à reprodução do seu modo de vida.

No tratamento do problema algumas categorias foram mobilizadas no sentido de apreender as diferentes racionalidades envolvidas na disputa pelos
1 Este artigo foi contemplado com $01^{\circ}$ lugar do Prêmio Lévi-Strauss, edição 2016 - modalidade artigo, promovido pela Associação Brasileira de Antropologia (ABA)

$2 \quad$ Projeto de pesquisa financiado pela FAPEMA entre 2013 e 2015 , do qual participei como bolsista PIBIC/ FAPEMA entre 2013 e 2014.

3 Gaúcho é uma denominação genérica atribuída àqueles que se dedicam ao cultivo da soja, não apenas aos que vieram do Rio Grande do Sul, mas também produtores oriundos de diversos lugares das regiões Sul, Sudeste e Centro Oeste do país e que hoje se expande para o Leste do Maranhão e já atingem, com seus monocultivos, até mesmo as áreas de floresta no Pará. Para maiores detalhes sobre essa categoria vide Paula Andrade, (2008) e Gaspar (2010). Para entender a expansão da soja no Maranhão e suas implicações ver Carneiro (2008)

4 Como mencionado por Paula Andrade (2008), as áreas de chapada são apropriadas pelas unidades de produção camponesa para a caça, coleta de frutos e plantas medicinais, assim como a criação de animais. As caças mais comuns nessas áreas são o tatu, cotia, catitu, peba e outros. Os frutos mais procurados são o bacuri, o pequi, o murici, dentre outros. Além desses, o mel-que também é fundamental à dieta das famílias-e as ervas medicinais são igualmente explorados. 
mesmos espaços estratégicos da área que hoje corresponde à Resex. Adotamos como aporte teórico as discussões relacionadas com os conflitos socioambientais, as formas de resistência cotidiana e também sobre os dispositivos de governança, gestão de recursos ambientais e governança territorial (Arns, 2010; Corezola, Oliveira e Almeida, 2010; Torre, 2010; Teisserenc, 2014). Assim, no contexto de funcionamento da unidade de conservação, buscamos refletir sobre as tensões geradas pelas formas de governança, a partir da confrontação entre o modelo adotado pelo Estado e aquele pensado pelas famílias dos distintos povoados que integram a Reserva Extrativista Chapada Limpa, levando em consideração as dimensões territorial e ambiental.

O artigo está organizado em três partes: na primeira parte buscamos fornecer através das narrativas locais, os elementos que caracterizaram a história de ocupação do povoado Juçaral. Na segunda, apontamos alguns aspectos referentes aos enfrentamentos aos pretensos proprietários e gaúchos e também à mobilização coletiva das famílias para a criação da Reserva Extrativista Chapada Limpa. Na terceira, dedicamos atenção às formas de manejo e uso dos recursos provenientes das transformações ocorridas dentro da UC, relativas à governança ambiental e territorial, uma vez que elas também transformam e influenciam as práticas dos grupos familiares em relação ao território em que vivem e ao ambiente de que fazem uso.

\section{HISTÓRIA DE OCUPAÇÃO DE POVOADO JUÇARAL E OS PROBLEMAS DAS LOCALIDADES VIZINHAS}

Desde os primeiros contatos com os interlocutores, as suas narrativas apontavam que as primeiras famílias do povoado ocuparam essas terras na década de 1960. Mencionaram que Pedro Ribeiro teria sido um dos primeiros moradores de Juçaral. Segundo os relatos, após ter fixado residência e desenvolvido atividades agrícolas, outras famílias passaram a se instalar no local. Assim como Pedro Ribeiro, essas famílias eram também provenientes do estado do Piauí, e se instalaram na região, em busca de terras livres (Andrade, 1973), onde seus descendentes permanecem até hoje.

Com o desenvolvimento da pesquisa, pude compreender que essa migração tem relação com os problemas sociais decorrentes de grandes períodos de seca e de concentração fundiária, fatores que sempre afligiram a região nordestina, como observou Andrade (1973) em seus estudos sobre o processo de ocupação territorial do Maranhão. Aos desafios próprios desse contexto, acrescentam-se o desejo de melhorar a qualidade de vida e a busca por condições para garantir a manutenção dos integrantes das unidades familiares. A fim de alcançar esses objetivos, os chefes de família saíam em busca de áreas disponíveis para cultivar 
livremente (Andrade, 1973; Velho, 1972).

Um detalhe a ser observado é que embora Seu Pedro Ribeiro seja apontado como suposto dono de Juçaral, os interlocutores informaram que as famílias que residiam em tais terras não pagavam renda (em produto) pelo uso. Os relatos evidenciavam qualidades atribuídas ao seu Pedro Ribeiro, como aquele que ofereceu condições não só para a reprodução das áreas de cultivo, mas também para a coesão social das famílias.

Outro aspecto relacionado ao controle do território ${ }^{5}$ é a falta de demarcação de terras no Leste do Maranhão. Em relação à aquisição de terras e registros irregulares para o apossamento ilegítimo de terras, Shiraishi (1995) aponta que muitas dessas aquisições foram sustentadas por mecanismos de grilagem, como o que ocorreu em Juçaral.

Aparece nos relatos que Pedro Ribeiro se endividou e não teve mais condições de pagar os impostos da terra e, por conta disso, cedeu uma parte da área que corresponde ao povoado Juçaral - cerca de 50 braças $^{6}$ - para Mudiquinho Vieira, que à época era prefeito de Chapadinha, em troca do pagamento dos impostos devidos. Segundo os relatos, além da área cedida na negociação com Pedro Ribeiro, Mudiquinho Vieira açambarcou outras áreas e passou a se dizer dono delas. A situação descrita é fato corriqueiro para as autoridades do Estado do Maranhão, uma vez que alegam não poder fazer nada para impedir o avanço dessas fraudes, sob o argumento de falta de recursos para exercer a devida fiscalização (Paula Andrade, 1995; Shiraishi Neto, 1995).

Com relação aos outros problemas observados envolvendo famílias dos povoados vizinhos Chapada Limpa I e Chapada Limpa II, destacamos os relacionados às atividades extrativas e a obrigatoriedade de dividir o produto dessa atividade, identificado pelos trabalhadores como bacuri de meia ${ }^{7}$, ocorrido no povoado Chapada Limpa I entre 2003 e 2004. De acordo com os interlocutores, o problema do pagamento de renda da terra e da exploração do trabalho das famílias por meio do chamado bacuri de meia, exigências dos irmãos Gilvan e Pedro Fonteles (pretensos proprietários de Chapada Limpa I), acabaram definindo uma situação limite que fez com que seu Raimundo Beata (morador de Chapada Limpa I) iniciasse a recusa das famílias em entregar os bacuris segundo esse sistema. Cansado daquela situação de exploração, deixou de realizar tal divisão, demonstrando assim, coragem em enfrentar aquele que se dizia proprietário da terra. Essa iniciativa de seu Raimundo Beata pode ser entendida como uma forma de resistência cotidiana, tal como sublinhado por James Scott (2002).

Dialogando com Scott (2002), essa forma de resistência individual abriu espaço ao questionamento do direito de propriedade dos pretensos proprietários e a recusa dos demais integrantes das famílias de Chapada Limpa I de continuar pagando renda pela terra e entregar a metade da extração dos bacuris.
5 O sentido de território aqui adotado inspira-se em Paul Little (2002: 3) e diz respeito ao "esforço coletivo de um grupo social para ocupar, usar, controlar e se identificar com uma parcela específica de seu ambiente biofísico, convertendo-a assim em seu 'território"'.

6 Braça é uma unidade de medida local, de acordo como são empregadas adquire designação própria e não possui um valor definido, o que varia de local para local. Em Juçaral uma braça corresponde a 2,20m.

7 O que caracteriza o chamado bacuri de meia é a entrega obrigatória pelo trabalhador da metade do bacuri coletado ao pretenso proprietário da terra, como forma de pagamento de renda pelo uso da terra. 
Diante dos interesses antagônicos, a posição dos membros das unidades familiares do povoado Chapada Limpa I acabou assumindo as características de um enfrentamento declarado. De um lado a sobrevivência das famílias que historicamente viviam naquela área e dependiam das terras para assegurar a reprodução material de seus membros; de outro o pretenso proprietário, que desejava continuar explorando as famílias mediante cobrança de renda pelo uso da terra. Segundo os relatos dos interlocutores, o caso foi objeto de intervenção da Justiça e ficou constatado que os pretensos proprietários de Chapada Limpa I não tinham o título de propriedade das terras que alegavam como suas. A partir desse momento as famílias de Chapada Limpa I deixaram de realizar a divisão do bacuri, o que aumentou a renda dos seus membros, uma vez que o resultado da coleta do fruto na chapada passou a ficar integralmente com elas.

Além desses enfrentamentos em Chapada Limpa I, relacionados com pagamento de renda por meio do chamado bacuri de meia, destaca-se o ocorrido no povoado Chapada Limpa II, em 2004. Tal problema refere-se à supressão da vegetação nativa e a derrubada de um antigo bacurizeiro de sessenta galhos ${ }^{8}$, pelo pretenso proprietário chamado Manuel Lira.

A derrubada de áreas de chapada está relacionada com a presença de gaúchos na região. Ele pretendia desmatar a área que dizia ser sua para posteriormente vendê-la aos denominados gaúchos. Essa iniciativa de Manoel Lira causou insatisfação coletiva e o enfrentamento dos gaúchos por parte dos moradores de Juçaral, que na época ameaçavam desmatar amplas áreas de chapada no povoado para dar lugar ao plantio de soja, conflito também ocorrido em 2004.

Segundo os relatos dos interlocutores, o bacurizeiro derrubado era considerado o mais antigo e por ter sessenta galhos, aspecto pouco encontrado em árvore desse porte, se sobressaia entre os demais. Por ser frondoso, ele servia como abrigo para os que transitavam pela região e também funcionava como ponto de localização. Era conhecido inclusive por pessoas de outras localidades. Por ser bastante apreciado pelas famílias, possuía grande valor simbólico.

O conflito em Juçaral ocorreu porque outro pretenso proprietário, Evaldo Vieira, prometeu vender uma parte da terra aos moradores pelo crédito fundiário. No entanto, não cumpriu o acordo com as famílias e vendeu a área para um gaúcho chamado Volmir Follmer. Assim, as famílias do povoado Juçaral ao se sentirem ameaçadas diante da possibilidade de perderem as áreas de chapada, indispensáveis à sua reprodução material e social, se dirigiram ao STTR de Chapadinha para denunciar a situação e encontrar uma forma de assegurar a permanência das famílias no território. Ante a ameaça de perder suas terras, os trabalhadores acabam adotando medidas no sentido de defendê-las. Denunciar o problema e pedir apoio do STTR na defesa das terras e da chapada podem ser lidas como formas de resistência cotidiana, nos termos sublinhados por James Scott (2002).
8 Esse bacurizeiro é bastante referenciado pelas famílias, tendo um importante significado simbólico. O fato de possuir sessenta galhos, - condição rara, segundo os trabalhadores-é outro fator que agrega singularidade a ele. 
Segundo os interlocutores, a cobrança exorbitante do aluguel da terra para implantação de roçados e a realização do extrativismo pelas famílias do povoado Chapada Limpa I por um suposto proprietário; o conflito no povoado Chapada Limpa II, que ocasionou tanto a supressão da vegetação nativa como a derrubada de um antigo bacurizeiro, ocorrido em 2004 por outro proprietário; e a ameaça de derrubada de áreas de chapadas no povoado Juçaral, ocorrido também em 2004, são eventos mencionados como os principais justificadores para a mobilização coletiva das famílias, para a criação da Reserva extrativista Chapada Limpa.

\section{MOBILIZAÇÃO COLETIVA PARA CRIAÇÃo DA RESEX CHAPADA LIMPA}

As situações identificadas anteriormente são consideradas como fatores que concorreram para a mobilização das famílias das localidades Chapada Limpa I, Chapada Limpa II e Juçaral. O objetivo principal dessa movimentação das famílias foi o de impedir a devastação das áreas de chapada pelos chamados gaúchos, diante da possibilidade da transferência de terras por parte dos pretensos proprietários. Ressaltamos que em alguns momentos, nas situações de conflito, ocorreram enfrentamentos diretos, seja com os pretensos proprietários, seja com os gaúchos. Nestes contextos, houve uma mobilização das famílias do povoado contra uma operação de desmatamento que estava sendo realizada em áreas utilizadas pelas famílias dessa localidade. Nesse sentido, cabe destacar as formulações de Acserald (2004: 07) ao afirmar que na "perspectiva das ciências sociais críticas, não é possível separar a sociedade e seu meio ambiente", pois cada relação é dotada de sentido específico, e as interações se verificam tanto material como socialmente.

O enfretamento entre os segmentos camponeses e os gaúchos, a princípio sugere uma relação de poder desigual, porém o desenrolar do conflito, alterou toda a situação, semelhante àquela estudada por Souza Filho (2013) ao sublinhar o conflito entre os quilombolas de Mamuna e a Alcântara Ciclone Space'9. Embora sejam situações distintas em termos sociais e geográficos, e apesar da existência de uma relação de força desigual, no caso de Juçaral ocorreu uma situação semeIhante. Segundo Souza Filho (2013: 107) "o que era apontado como irreversível, foi evitado pela reação das famílias ao se verem ameaçados em sua reprodução material e social". Ainda que as relações de poder indicassem um desequilíbrio nesse enfretamento, os trabalhadores se viram diante de uma situação-limite, já que o que estava em jogo era a garantia da permanência em seus territórios e a manutenção das áreas de chapada, historicamente utilizadas pelas famílias.

Nessa perspectiva, considerando as ponderações de James Scott (2002) as formas cotidianas de resistência, compreendem as diversas maneiras de defender-se em um determinado contexto. Desse modo, em um desses momentos de ameaça de devastação de extensas áreas de mata nativa, os moradores de
9 O referido estudo relaciona-se a trabalhos realizados pelo autor a partir de pesquisas desenvolvidas no município de Alcântara, procurando dar conta dos diferentes problemas enfrentados por famílias quilombolas localizadas em diferentes zonas do município, decorrentes da implantação do Centro de Lançamento de Alcântara na década de 1980. 
distintas localidades e os membros do Sindicato de Trabalhadores e Trabalhadoras Rurais de Chapadinha-STTR, se dirigiram às chapadas, munidos de facões, foices e outros instrumentos de trabalho para impedir a devastação levada a cabo pelos chamados "correntões" dos gaúchos, que consistem em grandes correntes atadas a tratores e usadas para derrubada da vegetação nativa. A partir dessa iniciativa, pode-se perceber que a ação coletiva das famílias de Juçaral revelou "a capacidade de associação dos agentes sociais“ (Souza Filho, 2013: 113).

Com relação ao enfrentamento, convém ressaltar que os moradores conseguiram evitar a continuidade do trabalho dos encarregados de promover o desmatamento, impedindo desse modo, qualquer tipo de acesso às terras por parte dos sojicultores. Esse episódio provocou grandes desdobramentos a ponto do pretenso proprietário acionar a polícia para acompanhar o trabalho dos tratores, porém, o embargo das obras pelos moradores foi mantido, propiciando deste modo, a abertura de processo por parte de um sojicultor do estado do Paraná para assegurar o direito de acesso à propriedade que reivindicava como sua.

Essa situação de conflito revela os interesses em jogo, uma vez que a área era pretendida pelos chamados gaúchos e também reivindicada pelas famílias que há décadas moravam na localidade. Sobre a utilização dos recursos, essas famílias se caracterizam por apresentar um modo de vida peculiar que permite uma apropriação equilibrada dos espaços e dos recursos naturais, permitindo, assim, um impacto menor, se comparado àquele provocado pelos novos agentes econômicos que se instalam na região.

Zhouri e Laschefski (2010) reforçam a tese de que os grandes agentes econômicos disputam áreas com os segmentos camponeses, principalmente porque veem nesses espaços condições favoráveis para o desenvolvimento de seus empreendimentos. Nesse sentido, cabe sublinhar a perspectiva salientada por Little (2002), que considera a resistência como uma das respostas mais comuns na história da expansão da produção de commodities (soja).

Diante do avanço dos agentes do agronegócio, as famílias situadas historicamente na região se organizaram e estabeleceram estratégias no sentido de frear a destruição das chapadas. Tais mobilizações permitiram que as famílias buscassem meios para defender os seus territórios e conservar os ambientes indispensáveis à reprodução do seu modo de vida (material e social). Nesse sentido, a mobilização ganhou força e contou com o apoio do STTR e órgãos ambientais oficiais para transformar essas áreas de tensão social em uma Reserva Extrativista de Uso Sustentável.

Diante desse quadro, para o entendimento do interesse em inserir a questão ambiental no universo da mobilização das famílias, vale recuperar as reflexões de Leite Lopes (2006) no que se refere à "ambientalização dos conflitos", uma vez que os questionamentos sobre os impactos da agressiva devastação de áreas de 
chapadas foram trazidas ao debate público. De acordo com o autor, o termo "ambientalização" passa a fazer parte do discurso das populações atingidas como estratégia de interesses e reivindicações. Nesse sentido, nas questões apontadas pelos entrevistados, os funcionários do IBAMA (a época) compartilharam da mobilização em favor da preservação dos ecossistemas.

Souza Filho (2014: 49) aponta que "o conflito não nasce, portanto, motivado por razões ambientais, torna-se ambiental, nos seus desdobramentos, por motivos estratégicos". Assim sendo, conforme o autor sublinha, o que deve ser levado em consideração, portanto, é a argumentação dos moradores de Juçaral associada ao discurso de preservação, pois o que se observa segundo os relatos, é que essa foi a melhor maneira de obter o que almejavam, já que foram orientados pelo órgão ambiental.

Convém lembrar que o povoado Juçaral foi pioneiro na luta dentre os outros povoados, visto que sua luta ganhou mais destaque, uma vez que houve um enfrentamento direto. Destaque-se ainda, que foram os moradores desse povoado que buscaram apoio e alternativas para minimizar os danos provocados pelos chamados gaúchos. Segundo os relatos dos interlocutores foi somente após o enfrentamento realizado pelas famílias do povoado Juçaral, que as famílias dos outros povoados ampliaram a luta e criaram suas respectivas associações de moradores, tendo sido auxiliados pelo STTR. Dessa maneira, o processo de implantação da Resex, cumpriu distintas etapas: a solicitação formal dos moradores de Juçaral por meio de sua associação; vistoria técnica do IBAMA para levantar o potencial da área e de seus recursos; elaboração do laudo socioeconômico e biológico e consulta pública aos moradores da área para implantação da Resex.

Como resultados desse processo de luta das famílias, no dia 26 de setembro de 2007, o então presidente Luiz Inácio Lula da Silva aprovou o Decreto de criação da Resex Chapada Limpa, unidade de conservação de uso sustentável localizada no município de Chapadinha/MA, com uma área de 11.971,24 hectares. Cabe destacar que apenas dezessete povoados foram beneficiados com a criação da Resex, "sendo a quinta reserva extrativista criada no Maranhão, sobretudo, a primeira do bioma cerrado" (Souza Filho, 2014: 55).

\section{COVERNANÇA AMBIENTAL E TERRITORIAL: O USO DOS RECURSOS} ANTES E DEPOIS DA CRIAÇÃO DA RESEX CHAPADA LIMPA

Superados os problemas com os pretensos proprietários e os agentes do agronegócio, e uma vez criada a Resex Chapada Limpa, caberia compreender os problemas relacionados com as formas de governança a partir da confrontação entre o modelo adotado pelo Estado e aquele pensado pelas famílias dos distintos povoados que integram a RESEX. Para tanto serão observados, em termos com- 
parativos, as formas de uso dos recursos pelas famílias tanto antes como depois da criação da Resex.

Em se tratando de reservas extrativistas de uso sustentável isso implica levar em consideração os modelos postos em jogo com relação ao uso e a conservação dos recursos: aquele definido pelos órgãos gestores e aquele dos atores sociais usuários dos recursos disponíveis na Unidade de Conservação.

A própria existência de uma UC reforça a ideia de compreender o que Arns (2010) chama de "dispositivos de governança", já que a participação do ICMBio como gestor da unidade de conservação tem gerado expectativas negativas pelas famílias em função das novas regras propostas de uso dos recursos naquele território. O objetivo, portanto, é entender em que medida a criação da Resex interferiu na autonomia dessas famílias.

Ao pensar as formas de organização social e econômica dessas famílias, é importante destacar que uma vez decretada à área como unidade de conservação, o Estado passou a atuar como co-gestor e, nesse caso, a maneira de olhar e agir em relação ao mesmo espaço natural começou a ser diferenciado. Novas regras passaram a orientar a relação com os recursos e alguns espaços começaram a ser pensados na lógica de natureza intocada (Diegues, 2004).

Nesse contexto, a criação da Resex Chapada Limpa fez aflorar um novo desafio: "relacionar-se com o Estado sem que isso representasse uma perda de autonomia das famílias em relação ao uso dos recursos segundo as particularidades de sua organização social e econômica" (Souza Filho, 2014: 56).

Segundo Pierre Teisserenc (2014), governança tem a ver com um conjunto de práticas participativas, cuja finalidade é assegurar o desenvolvimento sustentável. No caso da Resex Chapada Limpa, a governança irá se efetivar através das tomadas de decisão do conselho deliberativo, ao qual cabe o co-gerenciamento dessas áreas segundo regras acordadas e legitimada pelo órgão gestor.

\subsection{OS MECANISMOS DE GOVERNANÇA}

A Reserva Extrativista de Chapada Limpa é uma área utilizada por famílias camponesas, cuja organização econômica baseia-se na articulação do extrativismo com a agricultura, caça e a criação de animais de pequeno porte. Desta maneira, o modelo de UC tem como objetivos básicos proteger os meios de vida e a cultura dessas populações e assegurar o uso sustentável dos recursos naturais.

Corezola et al (2010) chamam atenção nesse sentido, argumentando que "a governança territorial se expressa na capacidade, dos atores sociais gerarem resultados políticos e sociais para os territórios, compartilhando o poder de decisão do Estado e a sociedade civil" (Corezola et al, 2010: 90). Cabe destacar que antes da área ser decretada como Resex, os segmentos camponeses eram 
submetidos ao pagamento de renda pelo uso da terra, bem como à divisão de meia do bacuri com os proprietários. Apesar desses limites, as famílias tinham autonomia para tomar decisões sobre o tamanho da área de plantio, o que plantar e onde plantar. Combinavam, igualmente, as áreas de apropriação privada familiar (áreas de plantio) com aquelas de uso comum (áreas de chapada) onde realizavam as atividades extrativas e de criação de animais.

Com a criação da UC, os moradores que outrora estavam atrelados aos proprietários, passaram a ficar sujeitos aos regulamentos estabelecidos pelo ICMBio. Assim, foram introduzidas novas regras que regulam o uso dos recursos, limitando a autonomia das famílias das localidades sobre seus territórios. A transformação dessa área de tensão em unidade de conservação, acabou introduzindo essa contradição: liberdade em relação aos pretensos proprietários, mas limitação de autonomia em relação às tomadas de decisão relativas ao uso dos recursos pela participação do Estado como co-gestor. Mesmo assim, muitos interpretam essa mudança como positiva, pois foi introduzida uma nova forma de olhar para o território e tomar as decisões quanto ao uso dos recursos.

Vale ressaltar que embora as UCs estejam intrinsecamente voltadas à sustentabilidade das chamadas comunidades tradicionais, ao serem criadas elas também transformam e influenciam as práticas dos grupos sociais em relação ao território em que vivem e ao ambiente de que fazem uso. Assim, as novas regras introduzidas pelo órgão gestor da Resex colidem em muitos aspectos com aquelas operadas pelas famílias em relação ao uso dos seus territórios, interferindo na forma de uso e manejo dos recursos pelas famílias. Esses elementos oferecem as bases para pensar as dinâmicas adotadas pelos agentes envolvidos na gestão ambiental e territorial dessa unidade de conservação.

Todos esses aspectos apontam que a governança deve consistir no conjunto de práticas entre atores preocupados em promover uma capacidade coletiva de gestão social pautada na cooperação e seus benefícios. Nesse sentido, dialogando com Corezola et al (2010), as práticas costumeiras desse grupos sociais foram confrontadas por uma lógica distinta à operada por eles.

Segundo os integrantes das unidades familiares passou a existir al gumas divergências entre as regras estabelecidas pelo ICMBio e aquelas que orientavam as práticas das famílias em relação ao uso dos recursos. Por colidirem em alguns aspectos, isso não significou necessariamente a perda da autonomia das famílias, mas sim uma nova forma de orientar as tomadas de decisão. Mesmo nessa situação, apesar de algumas mudanças quanto à gestão do território (definição de áreas específicas para as atividades agrícolas, controle de atividades próximas às nascentes, definição de áreas residenciais, etc.) a autonomia das famílias, com algumas modificações, foi mantida após a criação da Resex.

Mas afinal, de qual governança estamos falando? Uma governança que res- 
tringe autonomia ou a possibilita de alguma maneira? Segundo os relatos dos interlocutores, existe uma ambivalência da governança ambiental, visto que por um lado ela fortalece o poder do ICMBio mas, por outro, confere certa autonomia às famílias, uma vez que podem conservar as regras de uso de recursos em determinados ambientes tal como operavam antes de criação da Resex, agora sem a ameaça de intervenção de um pretenso proprietário.

Apesar dessa presença incômoda e ambivalente do Estado, - no que se refere à autonomia das famílias - os moradores evidenciam compreensões muito bem definidas sobre os aspectos positivos da criação da Resex - quebra da sujeição, já que outrora estavam atrelados aos proprietários, mas também aspectos negativos, relacionados às mudanças nas atividades agrícolas, em função do que estabelece o plano de uso da Resex.

Segundo os interlocutores, antes da criação da Resex, cada povoado tinha seus limites demarcados. Tal limite era identificado pelo que denominam localmente de variantes. Os variantes marcavam, portanto, os limites identificados e reconhecidos pelos proprietários ou moradores. Ainda segundo os informantes, mesmo depois de decretada a área como unidade de conservação, as formas de uso dos recursos dentro dos limites territoriais de cada povoado foram mantidos pelas famílias que, mesmo adotando as antigas regras passaram a experimentar novos códigos e dinâmicas, desta feita determinadas pelo ICMBio.

É possível perceber nitidamente como gerenciam os limites do território no que diz respeito às áreas de bacurizais. Segundo os moradores, as áreas de ocorrência do bacuri são divididas entre povoados, respeitando-se os limites estabelecidos e reconhecidos por eles. Assim, o bacurizal de cada povoado é uma área de uso comum das famílias daquele povoado. Em outras palavras, os limites territoriais em relação apropriação dos recursos, como por exemplo, a área de bacurizal, antes da criação da unidade, baseava-se, no costume que, cada pessoa só poderia pegar o bacuri somente dentro do limite do seu povoado. Segundo as regras locais, não era permitida a entrada de moradores que não pertencesse ao povoado para colher o fruto.

Neste contexto, a apropriação dos recursos para esses moradores, remete a existência do que Souza Filho (2008) chama de normas costumeiras que são reconhecidas e acatadas por tal grupo. Porém, algumas pessoas burlavam os limites dos territórios expressando assim, tensões entre os moradores. Cabe ressaltar, que essas quebras momentâneas das regras não tem relação com o novo contexto de ser uma Resex. Já existiam antes mesmo de ter sido decretada. Nesses casos, as famílias adotam mecanismos próprios de resolução dos problemas derivados dessas situações. Muitos têm aproveitado inclusive a existência do conselho deliberativo para tratar daqueles casos nos quais as regras locais não conseguem dar conta. Nesse caso, a criação da Resex pode ser pensada 
como elemento positivo, pois podem combinar as regras locais com esses novos mecanismos de governança.

Com a criação da Resex o ICMBio introduziu novas regras para disciplinar o acesso aos recursos segundo outro entendimento de uso comum. O uso comum para o ICMBio, significava a apropriação igualitária dos recursos da natureza.

O sentido de comum, na perspectiva do órgão gestor parte do pressuposto de que todos têm direito de acesso aos recursos por tratar-se de uma unidade de conservação. Seguindo as indicações de que a reserva extrativista contribui para a manutenção do meio ambiente, além de proteger a reprodução de modo de vida das chamadas comunidades tradicionais, e promover a garantia dos territórios aos moradores locais, isso disseminou o pensamento de que todos teriam o direito de colher o fruto onde desejar, visto tratar-se de uma unidade de conservação.

Certamente aqui reside um problema fundamental que é o de confrontação com os fundamentos nativos de uso comum dos recursos dos territórios. $O$ gestor da Resex, ao mencionar que todas as pessoas teriam acesso livre aos recursos, independentemente de morar ou não em áreas de ocorrência do bacuri fez aflorar descontentamentos já que, anteriormente à criação da unidade, a regra era que cada pessoa só poderia colher o bacuri para vender, dentro dos limites do seu povoado. Neste contexto, Souza Filho (2008: 139) destaca que "apesar de o uso comum ser uma prática recorrente, existem normas erigidas pelo grupo que disciplinam o acesso a tais recursos". A síntese de pensamento proposto no plano de manejo é que se deve levar em consideração a forma peculiar do manejo praticada pelas chamadas comunidades tradicionais, assegurando deste modo, 0 seu saber sobre a natureza.

Segundo os interlocutores, essa posição dos gestores permitiu a introdução da prática da coleta dos frutos ainda na árvore, o que representava uma desvalorização do produto, tendo em vista que o bacuri ainda estaria verde. Conforme os interlocutores, essa prática era caracterizada como invasão, já que pessoas exerciam pressão sobre os estoques de bacuri, desrespeitando os acordos de uso dos bacurizais estabelecidos entre os povoados, bem como comprometendo a sustentabilidade dessas famílias.

Segundo os interlocutores, uma vez permitido o livre acesso, independente de residir ou não dentro dos limites dos povoados da Resex, isso ensejaria concorrência acirrada, promovendo uma disputa pelos recursos que poderia colocar em risco a própria existência da atividade extrativa e a obtenção de renda àqueles que sempre dependeram do extrativismo daquele fruto, visto que não conseguiriam coletar o suficiente para efetivar a venda e garantir recursos para atender às necessidades das famílias.

Para evitar o descontrole e o surgimento de conflitos entre as famílias, e devido à importância econômica do bacuri, as famílias que moravam nos limites 
da Resex estabeleceram um acordo, recuperando o antigo costume praticado por elas, ou seja, colher o bacuri apenas no povoado ao qual pertenciam. A recuperação da antiga prática, permitiu que controlassem as tensões que começaram a surgir, possibilitando a coleta do fruto como outrora realizavam, assegurando a sua comercialização.

Em relação à coleta do fruto, foram elaboradas algumas regras pelos povoados para compor o Plano de Utilização, sendo que o fruto só poderia ser coletado quando estivesse no chão, tendo caído de forma natural quando maduro. Aqueles que moravam em áreas que não existem bacuris somente poderiam entrar nesses espaços para coletar o fruto apenas para o consumo, mas antes de adentrar nessas áreas, teriam que comunicar às famílias que viviam no lugar de ocorrência do fruto.

Cabe ressaltar que com relação a isso a solução tomada pelos moradores foi a elaboração de um contrato de concessão firmado em ata entre as associações de Juçaral, Chapada Limpa I e Chapada Limpa II, realçando que permaneceria em vigor o antigo costume. Com isso, foram resguardados os direitos historicamente estabelecidos. Neste caso o que estava em jogo, expresso na tomada de decisão relativa à estratégia de acordar a antiga regra de acesso aos recursos, era a própria garantia da manutenção dessas famílias.

O problema foi posto em pauta e apresentado como um elemento que contradizia a norma instituída pelo ICMBio. Em outras palavras, essas tensões faziam referência às tentativas de criarem mecanismos de defesa dos recursos usados pelas famílias. Isso implica dizer, que mesmo tendo sido criada a Resex, e possuir um gestor vinculado ao órgão ambiental do Estado, alguns moradores continuaram a ter o controle sobre algumas porções do território da unidade de conservação. Castro (2000: 166) comenta "que o território é o espaço ao qual certo grupo garante aos seus membros direitos de acesso, de uso e de controle dos recursos". Desta forma, o controle dos recursos é regulado por normas específicas e instituídas para além da regra concebida pelo ICMBio.

Trata-se de um território apropriado e delimitado por grupos familiares que historicamente vivem e fazem uso dos recursos encontrados nos seus povoados. Segundo Torre (2010) governança é uma categoria polissêmica, o que implica aspectos particulares, como por exemplo, a participação. Esses espaços de participação coletiva e diferenciada abrem também possibilidades de convergência em termos de objetivos, mais também de divergência. Assim, governança é uma ferramenta de compreensão que pressupõe consenso em torno de determinado problema, o que implica o envolvimento de vários atores (sociais e institucionais).

É importante enfatizar que durante as conversas mantidas com os interlocutores, aparecia de modo recorrente, a expressão: "tudo aí melhorou um pouco". Com o desenvolvimento da pesquisa, pude compreender que a ideia 
envolvida na expressão referia-se aos benefícios que a Resex trouxe para as famílias, bem como a quebra da sujeição que outrora os mantinham atrelados aos pretensos proprietários. No tocante a essa questão, os interlocutores enfatizaram algumas alterações positivas na organização social e econômica de Juçaral em função da aplicação do plano de uso e manejo dos recursos existentes na unidade de conservação.

Durante a pesquisa, as narrativas dos moradores remetiam às mudanças em relação às atividades agrícolas, extrativas, criação de animais, caça, e outros. Segundo os interlocutores, após a criação da UC, as roças deveriam ser implantadas apenas nos locais indicados, no caso, as áreas de $\operatorname{carrasco}^{10}$ e chapada, obedecendo ao limite mínimo de cem metros, ou mais de distância da beira de riachos, nascentes, e onde não havia a presença de bacuri, babaçu e demais espécies de potencial extrativo; as roças poderiam ser implantadas por um ou dois grupos, cujo objetivo era a redução de áreas isoladas, promovendo o cooperativismo, evitando a fragmentação da vegetação, com vistas a promover o menor impacto possível; o local de implantação das roças deveria ser comunicado à associação de moradores, indicando a forma de limpeza e o tamanho da área utilizada.

Conforme o plano de manejo, recomendava-se utilizar também como áreas de roçado, terrenos degradados, com a finalidade de evitar a abertura de novas áreas, possibilitando o uso mais consciente do estoque de terras e também o pousio. Cabe destacar, que os segmentos camponeses que viviam ali já desenvolviam naquela região as suas atividades econômicas segundo seu sistema cultural antes mesmo da chegada dos gaúchos e do Estado. Apesar das alterações introduzidas, em função de ter sido criada a Resex, isso não significou uma modificação radical nas práticas das famílias. Tiveram que adaptar-se a uma nova situação tendo que combinar suas antigas práticas com aquelas apresentadas pelo Estado posteriormente à criação da unidade de conservação.

\section{CONSIDERAÇõ̃ES FINAIS}

O processo de criação da Resex Chapada Limpa possibilitou a identificação de algumas questões relacionadas à autonomia dos segmentos camponeses. As recuperações históricas sinalizam para dois momentos importantes: 0 anterior à criação da Resex e o posterior a ele. No que se refere à autonomia das famílias no momento anterior à criação da Resex, observamos que ela esteve sujeita à relação que as famílias do povoado Juçaral estabeleciam com os pretensos proprietários que ameaçavam a reprodução material e social das famílias. Diante disso, tem-se uma autonomia colocada num contexto específico de ameaça no qual aquele que se dizia proprietário usurpava parte daquilo que era produzido pelos segmentos camponeses, comprometendo assim, a manutenção das uni-
10 As áreas de carrascos, descrita pelos interlocutores refere-se a terreno íngreme e pedregoso. São locais de vegetação mais densa, embora apropriado para caça, não apresenta um solo fértil quanto os chamados baixões (áreas úmidas, apontadas como propícias para o cultivo) 
dades familiares. Foi possível perceber que quando se verificou o enfretamento com pretensos proprietários de terra, o que estava em jogo era a autonomia das famílias camponesas, que não podia ser usufruída em função das limitações impostas pela cobrança de renda pelo uso da terra.

O problema da autonomia ganhou contornos diferentes quando essa relação de subordinação - ainda que problemática, mas que garantia a permanência na terra - podia ser transformada em uma situação de expropriação definitiva por conta da presença de novos agentes econômicos interessados na terra, no caso os chamados gaúchos.

Essa possibilidade colocou em risco a própria reprodução material e social das famílias, já que a mudança de relação com os antagonistas - dos pretensos proprietários para gaúchos-mudaria todo o cenário social e ambiental onde as famílias estavam instaladas. Ainda que subordinados, a relação com os pretensos proprietários não colocava em risco os ambientes correspondentes às áreas de chapada. Já a presença dos gaúchos implicava uma perspectiva totalmente distinta, pois representava a possibilidade de uma mudança radical na paisagem a partir da supressão da vegetação nativa.

Interessa considerar que quando se cria uma unidade de conservação, altera-se também as práticas pré-existentes no que se refere ao uso dos recursos. Isso também propicia alterações na autonomia das famílias, uma vez que a criação da Resex implica a introdução de novas regras de monitoramento ambiental e territorial. Então, quando se cria uma unidade de conservação, se redefine o princípio de autonomia.

Cabe destacar, por fim, a importância da criação de uma unidade de conservação no cerrado maranhense. Para muitos, a criação da Resex, apesar de alguns problemas foi apontada como positiva, pois possibilitou um grau de autonomia que antes não possuíam em virtude da subordinação aos pretensos proprietários.

É importante ressalvar que as famílias camponesas que historicamente vivem e trabalham na região Leste do Maranhão, à medida que realizam o enfrentamento aos novos agentes econômicos que se instalam na região, além de lutarem para continuar exercendo o direito à autonomia sobre seus territórios, acabam cumprido um papel importante na conservação da biodiversidade existente no cerrado. Assim, a questão da autonomia nesse caso, se define como complexa em função dos desafios a serem superados em função da modificação dessas áreas de tensão social em uma unidade de conservação, e também pela existência de novas regras para o monitoramento ambiental e territorial da Resex Chapada Limpa. 
Diana Patrícia Mendes é Graduada em Ciências Sociais, com Bacharelado e Licenciatura Plena pela UFMA. Mestranda do Programa de Pós-Graduação em Ciências Sociais da UFMA. Membro do Grupo de Estudos Rurais e Urbanos (GERUR/UFMA).

Benedito Souza Filho é Doutor em Antropologia pela Universidad Autonoma de Barcelona. Professor do Departamento de Sociologia e Antropologia e do Programa de Pós-graduação em Ciências Sociais da Universidade Federal do Maranhão. Líder do Grupo de Estudos Rurais e Urbanos (GERUR/UFMA).

\section{REFERÊNCIAS BIBLIOGRÁFICAS}

ACSELRAD, Henri

2004 "Conflitos ambientais - a atualidade do objeto". In Conflitos ambientais no Brasil. Rio de Janeiro, Relume Dumará, pp. 07-35.

ANDRADE, Manuel Correia de

1973 Paisagens e problemas do Brasil. $4^{\mathrm{a}}$ ed. São Paulo, Brasiliense.

ARNS, Paulo César

2010 "Um olhar sobre os dispositivos de governança". Raízes

- Revista de Ciências Sociais e Econômicas. Campinas

Grande, UFCG, v. 28, n. 1, 2; v. 29, n. 1:121-131.

BURAWOY, Michel

2006 "Por uma sociologia pública". Política \& Trabalho-Revista de Ciências Sociais. Paraíba, UFPB, n. 25: 9-50.

CARNEIRO, Marcelo Sampaio

2008 "A expansão e os impactos da soja no Maranhão". In SCHLESINGER, S.; NUNES, S.P. e CARNEIRO, M.S. (orgs.). A agricultura familiar da soja na região Sul e o monocultivo no Maranhão: duas faces do cultivo da soja no Brasil. Rio de Janeiro, FASE, pp. 77-146. 
CASTRO, Edna

2000 "Território, biodiversidade e saberes de populações tradicionais". In DIEGUES, Antônio Carlos (org.). Etnoconservação: novos rumos para a conservação da natureza. São Paulo, Hucitec, NUPAUB/USP, pp. 165-182.

COREZOLA, Fernanda; OLIVEIRA, Carlos Douglas e ALMEIDA, Maria Graça 2010 "Desafios da governança territorial nos territórios incorporados ao programa territórios da cidadania". Raízes - Revista de Ciências Sociais e Econômicas. Campina Grande, UFCG, v. 28, n. 1, 2; v. 29, n. 1: 87-96.

DIECUES, Antônio Carlos

[1994] 2004 O mito moderno da natureza intocada. $4^{\text {a }}$ ed. São Paulo, Hucitec.

GASPAR, Rafael B.

2010 OEldorado dos gaúchos: deslocamento de agricultores do Sul do país e seu estabelecimento no Leste Maranhense. São Luís, dissertação de mestrado, Universidade Federal do Maranhão.

LITTLE, Paul E.

2002 "Territórios sociais e povos tradicionais no Brasil: por uma antropologia da territorialidade". Série Antropologia, Brasília, UnB, n. 322: 1-32.

LOPES, José Sérgio Leite

2006 'Sobre processos de 'ambientalização' dos conflitos e sobre dilemas da participação". Horizontes Antropológicos. Porto Alegre, v. 12, n. 25: 31-64.

PAULA ANDRADE, Maristela de

1995 "A produção de carvão vegetal e o plantio de eucalipto no leste maranhense: consequências da devastação do cerrado e da concentração fundiária para a economia camponesa". In CONCEIÇÃO, Francisco Conçalves da (org.). Carajás: desenvolvimento ou destruição? Relatórios de pesquisa. São Luís, Comissão Pastoral da Terra.

2008 Os gaúchos descobrem o Brasil: projetos agropecuários contra a agricultura camponesa. São Luís, Edufma.

SCOTT, James C.

2002 "Formas cotidianas da resistência camponesa", (tradução Marilda Menezes e Lemuel Guerra). Raízes-Revista de Ciências Sociais e Econômicas. Campinas Grande, UFCG, v.21, n. 1: 10-44. 
SHIRAISHI NETO, Joaquim

1995 "Grilagem de terra no leste maranhense". In CONCEIÇÃO, Francisco Conçalves da (org.). Carajás: desenvolvimento ou destruição? Relatórios de pesquisa. São Luís, Comissão Pastoral da Terra, 1995.

SOUZA FILHO, Benedito

2008 Os pretos de Bom Sucesso: terra de preto, terra de santo, terra comum. São Luis, Edufma.

2013 "Ovo briga com pedra: metáforas e conflitos socioambientais em Alcântara". In Os novos capitães do mato: conflitos e disputa territorial em Alcântara. São Luis, Edufma, 2013.

2014 "Conflitos e estratégias para a governança territorial: o caso da Resex Chapada Limpa". Revista Pós Ciências Sociais - Dossiê Sociedade, Ambiente e Covernança. São Luis, Edufma, v.11, n. 22: 43-59.

TEISSERENC, Pierre

2014 "Covernança territorial em reservas extrativistas".

Revista Pós Ciências Sociais - Dossiê Sociedade, Ambientee

Governança. São Luis, Edufma, v.11, n. 22: 19-41.

TORRE, André

2010 "Conflitos e governança dos territórios". Raízes - Revista de Ciências Sociais e Econômicas. Campina Crande, UFCG, v. 28, n. 1, 2; v. 29, n. 1: 109-120.

VELHO, Otávio Guilherme

1972 Frentes de expansão e estrutura agrária-Estudo do Processo de Penetração numa Área da Transamazônica. Rio de Janeiro, Zahar.

ZHOURI, Andréa; LASCHEFSKI, Klemens

2010 "Desenvolvimento e conflitos ambientais-Um novo campo de investigação". In: ZHOURI, Andréa e LASCHEFSKI, Klemens (orgs.). Desenvolvimento e conflitos ambientais. Belo Horizonte, UFMG. 


\section{ABSTRACT}

The advance of agribusiness in eastern Maranhão, facing the planting of soybeans, has led to the destruction of large areas of Cerrado, compromising the social and economic organization of the families residing in the zones of implantation of these enterprises. Taking this framework for analysis, this article seeks to understand the impacts of these projects in the region, as it proposes a reflection on the elements that justified the creation of the Chapada Limpa Extractive Reserve located in the municipality of Chapadinha / MA as a territorial defense strategy. The study also seeks to understand the challenges of governance, since the autonomy of families was limited by the participation of the State as co-manager.

Recebido em 4 de outubro de 2016. Aceito em 30 de março de 2017.

\section{KEYWORDS}

Extractive

Reserve. Impacts.

Agrarian conflicts.

Agribusiness.

Governance. 